\title{
Working together in lifestory telling for residents in aged care facilities: A qualitative study of staff/ family collaboration in aged care
}

\author{
Kaye Elizabeth Ervin, Maddalena Cross, Alison Koschel \\ Rural Health Academic Network, University of Melbourne, Victoria, Australia \\ Correspondence: Kaye Ervin. Address: PO Box 252, Cobram, Victoria, 3644, Australia. Email: \\ ervink@humehealth.org.au
}

Received: September 24, 2012

Accepted: November 28, 2012

Online Published: January 5, 2013

DOI : 10.5430/jnep.v3n6p102

URL: http://dx.doi.org/10.5430/jnep.v3n6p102

\section{Abstract}

Introduction: The cognitive deficits associated with dementia often preclude residents in aged care facilities from being able to communicate their life histories, preferences and needs and staff typically rely on family to provide this information. This project explored the opinions of staff and families of participating together in the process of life storytelling for residents.

Methods: Staff and families of residents with dementia in one aged care facility were invited to participate in lifestory telling. Semi structured interviews were then conducted with staff and families to explore their perceptions of working together.

Results: Negative aspects reported by staff was the perception that some families expectations of care were too high, while family members reported a lack of communication with staff.

Conclusions: Life story telling for residents provided a positive experience for participants, with reports that the process itself improved their relationships by increasing understanding.

\section{Key words}

Dementia, Family perceptions, Life storytelling, Residential aged care, Staff perceptions, Staff/Family relationships

\section{I ntroduction}

The aim of this project was to explore staff and family perceptions of working together to undertake lifestory telling for residents with dementia, and whether lifestory telling as an intervention improved care.

Lifestory telling is also commonly referred to as narrative medicine, memoir writing and biographical work, and is the intentional or planned effort to encourage people to think about, remember, share and record information about themselves ${ }^{[1]}$.

Lifestory telling involves recording relevant aspects of a person's past and present life with the aim of using this life story to benefit them in their present situation ${ }^{[2]}$. The potential benefits as an intervention for people with dementia and their 
families have been recognised for some time, in terms of promoting individualised care, improving assessment, building relationships between care staff and family carers as well as improving communication ${ }^{[3,4]}$.

The benefits for individuals, families/friends and for staff providing care include improving understanding of the individual, promoting relationships and facilitating delivery of person-centred care ${ }^{[5]}$. Previous research suggests that lifestory work resulted in improved understanding of patients, relatives and family carers by staff. The experience of doing life story work was overwhelmingly positive and there was some evidence that the delivery of care had become more person-centred as result ${ }^{[6]}$.

The person-centred model of care is espoused as the gold standard model for aged care settings ${ }^{[7,8]}$ where the focus shifts from task to the subjective perception of care from the residents view point. Person-centred practices hinge on having a good knowledge of the resident ${ }^{[8-10]}$.

Residents diagnosed with dementia are frequently unable to express their needs and preferences ${ }^{[11-13]}$ due to the associated cognitive deficits. Staff must then rely on family members to provide information about the resident to ensure care is tailored to the individual. It is important to understand staff and family perceptions of working together in lifestory work to explore barriers and enablers to this intervention for residents with dementia.

\section{Conceptual framework}

Narrative theories provided the conceptual framework for this study. Narrative approaches can include autobiography, biographies oral history and autoethnography ${ }^{[14]}$. Narration is part of everyday life and people have a desire to tell their stories and it is the stories people tell themselves and others, about their past and present lives, which helps to make sense of their life experiences. A person's identity is what provides the person with a sense of continuity, a sense of coherence and a sense of self. Drawing together the different life experiences helps to shape and give meaning to life as a whole, and this is called the Theory of Narrative Identity ${ }^{[15,16]}$.

\section{Method}

\subsection{Setting}

The site was a 30 bed publicly funded rural residential aged care facility, in which $50 \%$ of the residents had a diagnosis of dementia. The site is located in an agricultural district approximately one hours' drive from the nearest major regional centre. There were 44 staff employed at the facility at the time of the project intervention and interviews.

\subsection{Recruitment}

Prior to the intervention of lifestory telling, an information session outlining the broad project aims and processes, and in particular the process of life story telling, was held for staff, residents and their families and volunteers. Invitation to participate was by poster display in the facility, information at resident/relative and staff meetings and by mail out to each residents' responsible person.

\subsection{I ntervention}

Twelve staff members from the RACF voluntarily undertook a one day training course in lifestory telling and its benefits. The staff who undertook the training were eleven Endorsed Nurses and one Activities Coordinator (two staff members worked in both roles). Endorsed nurses in Australia undertake a one year undergraduate diploma to practice and Activity Coordinators a 26 week certified course. 
A palliative care nurse who trains and oversees a memoir writer's service facilitated this training focusing on life story telling for residents. The education session included information on barriers and enablers to collecting life stories.

Staff were encouraged to employ the 'Discovery Tool' a proforma developed by the Australian Aged Care Standards and Accreditation Agency Limited ${ }^{[17]}$ intended to collect resident’s preferences, background social and lifestyle information.

Staff then conducted lifestory telling activities with consenting resident's families and collated and presented the information in a user friendly format (including posters, quilts and booklets) in consultation with, and approved by, the resident or responsible person. In all there were 12 families who consented to participate in lifestory telling (one lifestory telling activity for each trained staff member). The information collated was then available to all staff and volunteers of the facility.

\subsection{I nterview participants}

Twelve weeks after the life story telling intervention was completed, recorded face to face interviews were conducted with participants who volunteered to attend. The participants were a sample of staff who had attended the training sessions and those who had not, plus family members of residents and volunteers from the RACF. Staff and volunteers who had not undertaken the training were invited for their unbiased view of observed changes in care following the lifestory telling intervention.

\subsection{Design}

A qualitative research design was utilised to elicit the required data. A semi-structured interview with a topic guide containing open ended questions was used. This method defines areas to be explored but also allows both the interviewer and interviewee to diverge from the main topics in order to pursue an idea in more detail ${ }^{[18]}$. Due to the small number of participants and size of the small rural town, all efforts are made to protect identities, and so demographics of the participants are not provided.

\subsection{Analysis}

Interviews were transcribed verbatim from the recordings and analysed to identify themes in the interviews. Thematic analysis is a method for identifying, analysing, and reporting patterns (themes) within data ${ }^{[19]}$. Once the interviews were transcribed, two researchers independently immersed and familiarised themselves with the data. They then began to generate initial codes from the data. This approach reduces the data. Codes are then grouped into broader themes allowing the interviews to be described and summarised. One independent researcher, not associated with the project used SPPS version 15, while the principal researcher themed the interviews by hand. The researchers then came together and discussed the themes until consensus was reached between the researchers and the data could be reduced no further.

\section{Ethics approval}

The research project was approved by the The University of Melbourne Human Research and Ethics Committee (Project No 1033333.1).

\section{Results}

\subsection{Participants}

There were ten participants who consented and were available to be interviewed. Five interview participants were staff who had undertaken training in lifestory telling and participated in the intervention, three were staff members who had not participated in the training or intervention and one family member who had consented to, and been involved in the lifestory 
telling intervention. The final participant was a volunteer in the facility who was not involved in the training or intervention. Family members and volunteers are referred to as non staff due to identification.

\subsection{Themes}

Data from interviews about life story telling identified four themes.

\subsubsection{Staff/ family relationships and communication}

The element of relationships and communication held both negative and positive perceptions. The negative views of staff and non staff were expressed mostly from those who were not involved in the intervention. One staff member commented:

“...it doesn't work with families....they have all these different expectations. We have meetings with families to try to be realistic but it doesn't work."

and

"The hardest thing to deal with is the family, it's not so much the resident, it's the family."

Staff members who were involved in lifestory telling, held more positive perceptions and commented:

"The family responded to me in a very positive way, they felt more confident in me and we have developed rapport. Even if I wasn't caring for their mum on that shift, if there was anything they wanted done, they'd seek me out."

and

"Listening, listening to the patient, listening to the person, to what they have to say. We don't usually listen."

and

"I definitely talk to the family more, and spend a bit more time with the resident themselves."

A non staff member, who did not participate in the intervention, commented that communication between staff and families is poor:

“It doesn't matter how many times I tell them, they just don't listen”

While other non staff involved in lifestory telling, commented on the relationship with staff:

“They're great, just the friendliness I think, they're all good, and yet you get some people complain, I don't know why."

\subsubsection{Care needs insight and strategies}

There were many staff and non staff comments about improved care that resulted from the lifestory telling, and a change in strategies to overcome behavioural and psychological symptoms of dementia related to better understanding. One non staff participant commented;

"The story's the girls did, I think were great, they hung them up on the walls and everyone loves them because you get some insight into their background."

Staff members involved in the training and intervention commented that; 
"The family have a lot of input, that can help bring the person back to you. It can help you organise activities that they may be interested in, or that might spark somethhing in them."

and

"Through his story I understood what he needed, not what we wanted, it's what he needed. It's had a major impact.”

and

"If she's agitated I try to talk about the good old days when she used to help her father with the horse and cart doing deliveries. I wasn't privileged to that information before. It helps manage her behaviour”.

Other staff who were not involved in the training and intervention held differing views about the benefits of lifestory telling for residents. One responded:

"Nothing's changed. I can't see any difference [in care practices]"

while another commented;

"Staff have more of an understanding of the person and start to see them as more human. Staff are more proactive with the dementia patients, there's more awareness."

\subsubsection{Staff training}

Both staff and non staff percieved the lifestory telling training to be valuable and something which should be continued and extended to all staff. Some comments were;

"I think it [lifestory telling] should be mandatory training. That's my opinion."

and

"It was inspiring [the training]. It gave you a little boost. It gave me insight into how to get people to open up."

"I think it's a valuable program, it's a pity more staff didn't participate."

and

"The more we got [lifestories] the better it would be. It helped us understand these people and the memoir writing seemed to spark the whole place up. It was great, really great, I loved it, particularly finding out what people did in a former life prior to coming here"

A non staff member commented on the lifestories and said;

"I see the staff read them and say 'Oh, I didn't know that'. It would be good if all staff did this training."

Another staff member who did not participate in the lifestory telling training or intervention commented;

"They reckon it's fantastic, everyone that I've spoken to, they reckon it was really good, they were very happy from my understanding." 


\subsubsection{Family participation}

All interview participants commented on the issue of family participation, both positively and negatively. While most welcomed the participation of families, some found it problematic to gain families cooperation, while another expressed that the involvement of families was damaging for residents with dementia.

"We invite families to special events, we encourage all families, and a lot of families chose not to come."

and

"I had difficulty getting photo's from the family, I asked them at the beginning, and they were always busy or couldn't find them.....as far as getting resources from them, it was very difficult."

One staff member, who was not involved in the intervention, commented;

"To tell the truth, every time the family comes in, behaviour [of residents] gets worse. Participation of families is a negative thing."

Positive perceptions included;

"It helped us understand not just the people, but their families. We need to get them involved in things they can be involved in.”

and

"The family knows that person better than the nursing staff, nobody knows those people better than their own family. The more information you gather about a resident, the more knowledge you have to equip you to deal with adverse situations."

A non staff participant commented;

“Everyone’s made welcome, it’s great.”

\section{Discussion}

This project reports a small study of staff, volunteer and family perceptions in one rural aged care facility which employed life story telling for it's residents with dementia. The small size of the study is acknowledged; however, the findings need to be seen in the light of previously published work in this area. This study employed a qualitative methodology, to generate a better understanding of the perceptions of staff and families in collaborating to tell residents life stories.

McKeown et al's ${ }^{[20]}$ literature review of life story telling describes many methods of using life story work. Predominantly the method used was staff collaboration with families or significant others through an interview format, as was the methodology of this study (though staff in this study received formal training to facilitate this). No single approach has been assessed as more effective, and is described as irrelevant given the aim.

The results were biased towards those who had participated in the lifestory telling project, with more respondents from this group. This group perceived greater benefits to the care provided to residents as a result of the intervention, compared to those who did not. Those who did not participate in the training and intervention reported that there was minimal or no difference in the care of residents following the lifestory telling project. This is an important finding, as most qualitative studies focus only on the participants of the storytelling itself. It remains unanswered whether the benefit of improved 
resident care through lifestory telling extends only to the staff who participated, through improved insight which is not transferrable to other staff of the facility, or if it is a misplaced perception of the effects. Staff who did participate in the training and intervention reported increased understanding and improved relationships with families, which in itself is a basis for greater uptake of this work.

This modest also study found that residential aged care staff (RAC) believed there are differing and competing expectations between staff and families in RAC settings, and furthermore that families expectations are too high. Staff report that they placed high importance on getting to know residents and their families and that lifestory telling increased understanding between staff and families, gave staff a better understanding of residents, fostered a closer relationship and increased families confidence in staff of the facility. Previous research reports that residential aged care settings are not conducive to constructive staff/family relationships ${ }^{[21,22]}$. A good relationship between staff and families in residential aged care facilities (RACF's) is essential to the provision of high quality care. Family and friends of residents are an extension of the person and their establishment of personhood which has long been recognised in the literature ${ }^{[9]}$. Lifestory telling provides a possible conduit to establishing constructive relationships in this setting.

Proponents of lifestory telling support the finding from this study, that the act of collaborating in life story work improves relationships between staff and family members ${ }^{[20]}$. Staff members who did not participate in the training and intervention of lifestory telling reported antagonistic attitudes towards families, and perceiving no benefit from families participation in resident care.

In this study and others ${ }^{[20,23,24]}$ the value of life story telling was seen predominantly in its capacity to humanize residents, described as having a better knowledge or understanding of the resident as a person - which is the very essence of person-centred care. Several studies have used life story telling with an aim of preserving the identity or personhood of the older person ${ }^{[3,23,24]}$ which is again the aim of person-centred care ${ }^{[12]}$.

Staff who participated in the lifestory telling described that life story telling allowed them to understand the person they were caring for in the context of their past and helped to explain present behaviour patterns (observed in residents with cognitive decline associated with dementia). This understanding also extended to families, with staff describing a better understanding of the residents families and their expectations, which has also been found in other studies ${ }^{[2,23,25]}$. Staff valued the life story telling not only as a resource to get to know the resident better, but as an enjoyable activity for all concerned.

Without exception previous research makes reference to life story work in helping staff to understand the resident, and viewing them as an individual. Life story telling is also reported to lead to more individualised care ${ }^{[26,27]}$ and identification of psychosocial needs that would otherwise remain hidden ${ }^{[28]}$. This factor is essential in the care of people with dementia who exhibit behavioural and psychological symptoms. This benefit was not reported by staff members who did not participate in the training and intervention.

Overall, the study demonstrated that the act of participating in lifestory work results in improved staff perceptions of families and the benefits of their partcipation in care. Furthermore, there was a perception among intervention participants that lifestory work improved resident care.

\section{Conclusions}

Findings from this study highlight the importance of lifestory work not only for the benefit of person-centred care practices, but for the flow on effect on staff/family relationships. Staff of RAC facilities and families working collaboratively to tell the stories of older people may help foster understanding between the parties, resulting in closer 
relationships. Further research, on a larger scale is needed to provide evidence of the positive changes that may assist in shaping and providing care and services for residents and their families in RAC facilities.

\section{Acknowledgements}

The project was funded by the Australian Government as part of the Evaluating Effectiveness of Participation Projects 2011.

\section{References}

[1] McKeown, J., Clarke, A., Repper, J., Life story work in health and social care: Systematic literature review. Journal of Advanced Nursing, 2005. 55(2): 237-247. PMid:16866815 http://dx.doi.org/10.1111/j.1365-2648.2006.03897.x

[2] Murphy, C., Crackin' lives: An evaluation of a Life Story Book Project to assist patients from a long stay psychiatric hospital in their move to community care situations. Unpublished report, 2000.

[3] Clarke, A., Hanson, E., Ross, H., Seeing the person behind the patient: enhancing the care of older people using a biographical approach Journal of Clinical Nursing, 2003. 12(5): 697-706. PMid:12919216 http://dx.doi.org/10.1046/j.1365-2702.2003.00784.x

[4] Bryan, K., Maxim,J. , Enabling care staff to relate to older communication disabled people. International Journal of Language and Communication Disorders, 1998. 33: 121-125. PMid:10343677 http://dx.doi.org/10.3109/13682829809179408

[5] Dementia UK: Improving quality of life, what a difference a story makes; usinglife story work to enhance care. http://www.dementiauk.org/information-support/life-story-work/, 2012. Accessed 24th Sept, 2012.

[6] Thompson, R., Realising the potential: Developing life story work in practice. Foundation of Nursing Studies Dissemination Series, 2010. 5. Available from: http://www.dementiauk.org/assets/files/info_and_support/Realising_the_Potential.pdf.

[7] Edvardsson, D., Winblad, B., Sandman, P., Person-centred care for people with severe Alzheimer's disease: current status and way forward. . Lancet Neurology, 2008. 7: 362-367. http://dx.doi.org/10.1016/S1474-4422(08)70063-2

[8] Chenoweth, L., King, M., Jeon, Y., Brodaty, H., Stein-Parbury, J., Norman, R., Haas, M., Luscombe, G. Caring for Aged Dementia Care Resident Study (CADRES) of person-centred care, dementia-care mapping, and usual care in dementia: a cluster-randomised trial. The Lancet Neurology. 8(4): 317-325. http://dx.doi.org/10.1016/S1474-4422(09)70045-6

[9] Brooker, D., What is person-centred care in dementia? Reviews in Clinical Gerontology. 2004; 13(3): 215-222. http://dx.doi.org/10.1017/S095925980400108X

[10] Fossey, J., Ballard, C., Juszczak, E., James, I., Alder, N., Jacoby, R. \& Howard, R. , Effect of enhanced psychosocial care on antipsychotic use in nursing home residents with severe dementia: cluster randomised trial. British Medical Journal, 2006. 332(March): 756-761. PMid:16543297 http://dx.doi.org/10.1136/bmj.38782.575868.7C

[11] Crotty, M., Whitehead, C., Lange, K.et al. Using the nursing home behaviour problem scale in an Australian residential care setting. . Australasian Journal on Ageing. 2004. 23(3): 150-5. http://dx.doi.org/10.1111/j.1741-6612.2004.00038.x

[12] Kitwood, T., Dementia reconsidered:The person comes first. 1997, Buckingham: Open University Press.

[13] Australian Government. TIME for dementia. hhtp://www.timefordementia.org/Home/. 2011 [cited 2011 26th August 2011].

[14] Holloway, I., and Freshwater, D. , Narrative research. Nursing Oxford: Blackwell Publishing, 2007. http://dx.doi.org/10.1002/9781444316513

[15] Polkinghorne, D., Explorations of narrative identity. Psychol Inq, 1996: 363-367. http://dx.doi.org/10.1207/s15327965pli0704_13

[16] Roesler, C., A narratological methodology for identifying archetypal story patterns in autobiographical narratives. J Anal Psychol., 2006: p. 574-586. PMid:16918800 http://dx.doi.org/10.1111/j.1468-5922.2006.00498.x

[17] The Aged Care Standards and Accreditation Agency, L., Discovery Tool, in Demystifying Dementia Care - Workplace Activities Guide. 2004.

[18] Elliott, B., Larson, J., Adolescents in mid-sized and rural communities: foregone care, perceived barriers, and risk factors.. Journal of Adolescent Health, 2004. 35(4): 303-309. PMid:15450544

[19] Braun, V., Clark, V., Using thematic analysis in psychology. . Qualitative Res Psychol 2006. 3(2): 77-101. http://dx.doi.org/10.1191/1478088706qp063oa

[20] McKeown, J., Clarke, A., Repper, J. , Life story work in health and social care: systematic literature review. Journal of Advanced Nursing, 2005. 55(2): 237-247. PMid:16866815 http://dx.doi.org/10.1111/j.1365-2648.2006.03897.x

[21] Bauer, M., and Nay, R. , Improving family-staff relationships in assisted living facilities: the views of family. Journal of Advanced Nursing, 2011. 67(6): 1232-1241. PMid:21306421 ttp://dx.doi.org/10.1111/j.1365-2648.2010.05575.x

[22] Haesler, E., Bauer, M. \& Nay, R., Constructive staff-family relationships in the care of older adults in the institutional setting. A systematic review. Australian Centre for Evidence Based Aged Care (ACEBAC), 2006.

Published by Sciedu Press 
[23] Hewitt, H., A life story approach for people with profound disabilities. British Journal of Nursing. 2000; 9(2): 90-95. PMid:11022432

[24] Holm, A.K., Lepp, M., Ringsberg, K.,, Dementia: involving patients in storytelling - a caring intervention. A pilot study. Journal of Clinical Nursing. 2005; 14(2): 256-263. PMid:15669935 http://dx.doi.org/10.1111/j.1365-2702.2004.01042.x

[25] Maas, M., Reed, D., Park, M., Specht, J. et al, Outcomes of family involvement in care intervention for caregivers of individuals with dementia. Nursing research. 2004; 53(2). PMid:15084992 http://dx.doi.org/10.1097/00006199-200403000-00003

[26] Heliker, D., A narrative approach to quality care in long term care facilities. Journal of Holistic Nursing. 1997; 15(1): 68-81. PMid:9146196 http://dx.doi.org/10.1177/089801019701500107

[27] Moos, I., \& Bjorn, A. , Use of the life story in the institutional care of people with dementia: a review of intervention studies. Ageing and Society, 2006. 26(3): 431-454. http://dx.doi.org/10.1017/S0144686X06004806

[28] Adams, J., Bornat, J., Prickett, M., You wouldn't be interested in my life, I've done nothing. Care planning and life history work with frail older women. Reveiwing Care Management of Older People, 1996. Jessica Kingsley Publishers, London: 102-116. 